\title{
Organ Sparing Surgery in Stage I Testicular Sex Cord Stromal Tumours: Results of a Small Series
}

\author{
Emanuela Trenti ${ }^{* 1}$, Armin Pycha ${ }^{1,2}$, Carolina D'Elia ${ }^{1}$, Evi Comploj ${ }^{1-6}$, Dorjan Huqi ${ }^{1}$, Esther Hanspeter ${ }^{3}$, Alexander \\ Pycha $^{4}$, Wolfgang Horninger ${ }^{5}$, Salvatore M Palermo ${ }^{1}$
}

${ }^{1}$ Department of Urology, Central Hospital of Bolzano, Italy

${ }^{2}$ Sigmund Freud University Medical School, Austria

${ }^{3}$ Department of Pathology, Central Hospital of Bolzano, Italy

${ }^{4}$ Department of Urology, Kantons Hospital Luzern, Italy

${ }^{5}$ Department of Urology, Medizinische Universitaet, Austria

${ }^{6}$ Department of Research, College of Health Care Professions Claudiana, Italy

Received: 㠿: November 20, 2018; Published: 制: December 04, 2018

*Corresponding author: Emanuela Trenti, Department of Urology, Italy

\section{Abstract}

Introduction: We present a small series of patients with stage I testicular sex-cord stromal tumours (TSCST), treated with organ-sparing surgery, which confirm its feasibility and safety in selected patients.

Materials and Methods: Between 2005 and 2016 a TSCST was diagnosed in 11 patients at our department. The mean age was 46.8 years (1483). Alpha-FP, HCG and LDH were assessed in all patients. During the operation frozen sections were request in order to choose the surgical strategy. A testis sparing surgery (TSS) was performed always in case of TSCST. A thoracic-abdominal computed tomography (CT) was performed after the surgery. The follow-up was scheduled according with the EAU guide-lines for testicular tumours.

Results: Alpha-FP, HCG and LDH were negative in all patients. The frozen sections showed a TSCST in 10 patients, which were treated with TSS. In 1 patient was performed an orchiectomy by seminoma in the frozen sections but the definitive histology showed a TSCST. The mean tumour size was $11 \mathrm{~mm}$ (7-40). The definitive histology showed no angio-invasion, severe nuclear atypia, margin infiltration, necrosis or high mitoses-index and the CT was negative in all cases. The mean follow-up was 43.8 months (10-108) and all patients remained free from disease.

Conclusion: TSCST represent 3-5\% of all testicular tumours. A malignant behaviour is reported in about $10 \%$ of cases. Because of their low incidence their management remain controversial. The potential malignancy may be a reason to perform an orchiectomy and TSS remains an option. Our small series shows that TSS could be safely performed by TSCST in frozen sections. By one or more pathological risk factors in the definitive histology a radical surgery should always be considered. Although the good prognosis of these tumours, we point out the need of a regular follow-up.

Keywords: Sex-Cord Stromal Tumour; Testis Sparing Surgery; Leydig Cell Tumour; Sertoli Cell Tumour; Granulosa Cell Tumour

Abbreviations: TSCST: Testicular Sex-Cord Stromal Tumours; HCG: Human Chorionic-Gonadotropin; LDH: Lactate-Dehydrogenase; TSS: TestisSparing Surgery; CT: Computed Tomography

\section{Introduction}

Testicular sex-cord stromal tumours (TSCST) arise from nongerminal cell-lines of the male testis: Leydig cell tumours are the most common subtype $(75-80 \%)$ but this group of tumours includes also Sertoli and granulosa cell tumours, mixed and undifferentiated tumours, thecomas and fibromas. They can occur at any age with a range from 12 to 76 years [1]. The most common clinical presentation is a palpable testicular mass but one third of patients presents gynecomastia, infertility, erectile disfunction or decreased libido. While most cases of TSCST are benign, a malignant behaviour with metastasizing potential is reported in approximately $10 \%$ of these tumours [2-6]. The identification of the favourable cases, performing frozen section analysis and using some histological findings, which can predict malignancy, can avoid an unnecessary orchiectomy [1-5]. We present a small series of patients with stage I TSCST, treated with organ sparing surgery, which confirm its feasibility and safety in selected patients.

\section{Materials and Methods}

Between 2005 and 2016 a TSCST was diagnosed in 11 patients at our department. The age ranged from 14 to 83 years (mean 46.8). The blood screening with alpha-fetoprotein (alfa-FP), human chorionic-gonadotropin (HCG) and lactate-dehydrogenase (LDH) was 
assessed preoperatively in all patients. No patient had hormonal disorders except one, who showed low testosterone levels and no patient presented gynecomastia. All patients underwent inguinal access to the testis. During the operation frozen sections were requested, as usual in our department, in order to choose the definitive surgical strategy. A testis-sparing surgery (TSS) was performed always in case of TSCST, waiting for the definitive histology, instead to perform a primary radical orchiectomy. A thoracic and abdominal computed tomography (CT) was performed after the surgery in all patients. The follow-up was scheduled according with the European Association of Urology guide-lines for testicular tumours.

\section{Results}

All lesions were intraparenchymal and detected in ultrasound. Alpha-FP, HCG and LDH were negative in all patients. The intraoperative histology showed a TSCST in 10 patients, which were treated with TSS. In 1 patient was performed an orchiectomy, because the frozen section suspected a seminoma, but the definitive histology showed a TSCST. The tumour-size ranged from 7 to $40 \mathrm{~mm}$ (mean $11.3 \mathrm{~mm}$ ). There was no evidence of angioinvasion, margin infiltration or necrosis in the definitive histology. The mitosis-index was $<1 \%$ in all patients (Figures $1 \& 2$ ). All postoperative courses were uneventful, and the patients were discharged one day after the operation without complications. After discharge one patient developed an intratesticular hematoma, recovered within 4 weeks without any treatment. The CT showed absence of lymph node enlargement or distant metastases in all patients. Follow-up ranged from 18 to 108 months (mean 46.3 months), every 6 months for 5 years with ultrasound of the testis and ultrasound of the abdomen alternated with CT and then every year with ultrasound of the testis and ultrasound of the abdomen. All patient is free from disease and alive except one, who died after 108 months for other reasons (Table 1).

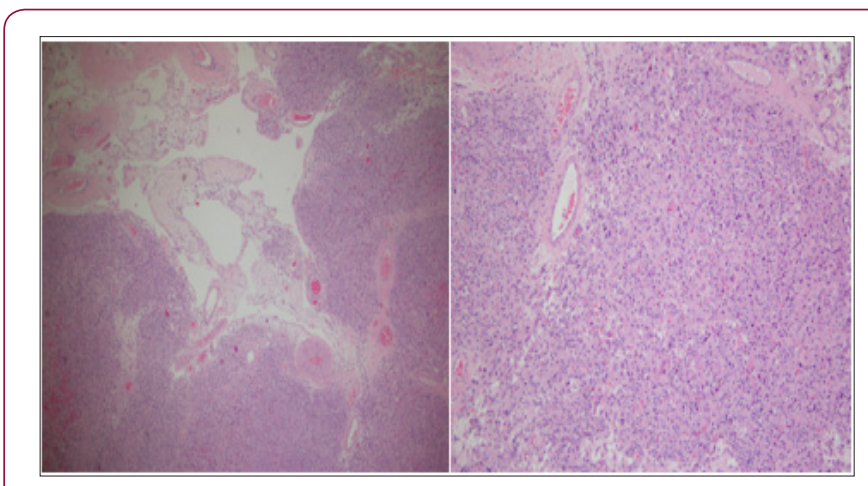

Figure 1: On the right side hematoxylin and eosin staining of a Leydig cell tumor.

In the upper left corner vessels and atrophic seminiferous tubules are visible; all around the neoplastic cells. On the left side $10 \mathrm{x}$ magnification of the bottom right corner.

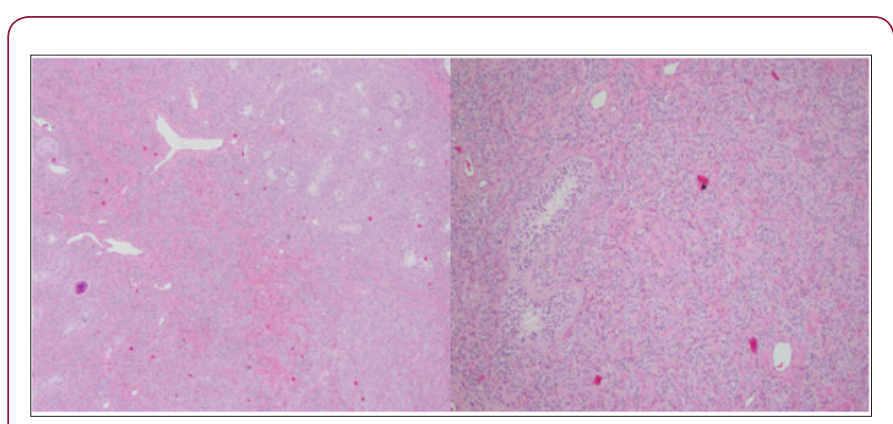

Figure 2: On the right side hematoxylin and eosin staining of a Sertoli cell tumor: the seminiferous tubules surrounded by neoplastic cells are visible. On the left side $10 \times$ magnification of the upper right corner.

Table 1: Characteristics of the Operated Patients.

\begin{tabular}{|c|c|c|c|c|c|c|}
\hline \multicolumn{7}{|c|}{ Characteristics of the Operated Patients } \\
\hline Patient & Age & Type & Diameter & Treatment & Risk factors & Follow up \\
\hline 1 & 46 yr. & Leydig & $7 \mathrm{~mm}$ & Elective TSS & none & $18 \mathrm{months}$ \\
\hline 2 & $32 \mathrm{yr}$. & Granulosa & $15 \mathrm{~mm}$ & Elective TSS & none & $18 \mathrm{months}$ \\
\hline 3 & $14 \mathrm{yr}$. & Sertoli & $12 \mathrm{~mm}$ & Elective TSS & none & 18 months \\
\hline 4 & $51 \mathrm{yr}$. & Leydig & $7 \mathrm{~mm}$ & Elective TSS & 1 (age) & $36 \mathrm{months}$ \\
\hline 5 & $52 \mathrm{yr}$. & Leydig & $8 \mathrm{~mm}$ & Orchiectomy & 1 (age) & $24 \mathrm{months}$ \\
\hline 6 & $24 \mathrm{yr}$. & Sertoli & $8 \mathrm{~mm}$ & Elective TSS & none & 30 months \\
\hline 7 & $83 \mathrm{yr}$. & Leydig & $9 \mathrm{~mm}$ & Elective TSS & 1 (age) & $48 \mathrm{months}$ \\
\hline 8 & $41 \mathrm{yr}$. & Leydig & $6 \mathrm{~mm}$ & Elective TSS & none & $56 \mathrm{months}$ \\
\hline 9 & $69 \mathrm{yr}$. & Leydig & $40 \mathrm{~mm}$ & Elective TSS & 1 (age) & $82 \mathrm{months}$ \\
\hline 10 & $35 \mathrm{yr}$. & Leydig & $8 \mathrm{~mm}$ & Elective TSS & none & $108 \mathrm{months}$ \\
\hline 11 & $52 \mathrm{yr}$. & Leydig & $5 \mathrm{~mm}$ & Elective TSS & 1 (age) & $72 \mathrm{months}$ \\
\hline
\end{tabular}




\section{Discussion}

TSCST are very rare tumours of the male testis, accounting from 3 to $5 \%$ of all testicular neoplasms. From a review of the literature the median age of presentation is 35 years with a range from 12 to 76 years [1]. The most common clinical presentation is a palpable testicular mass, even if the incidental finding of asymptomatic and non-palpable lesions is now more frequently detected, due to the increased use of the ultrasonography [2]. Due to their endocrinological activity, erectile dysfunction, infertility or decreased libido could be present in one third of patients. A. gynecomastia is also present in about $15 \%$ of the patients [3-7]. The great majority of these tumours shows a good clinical outcome, but a malignant behaviour has been reported in about $10 \%$ of all cases $[1,8,9]$. The retroperitoneal lymph nodes are the most common metastatic regions, but liver, lung and bone metastases have also been described. $[4,5,10]$. In these cases, the progression of the disease is rapid and the prognosis poor, due to scarce response to CHT or RT [2].

Because of his low incidence and the lack of data with prospective studies, their management remains controversial: the EAU guide-lines recommend an organ-sparing procedure in every small ultrasound-detected, non-palpable intraparenchymal lesion to obtain a histological diagnosis and, in case of malignancy, to perform a secondary orchiectomy, even if they don't give a cut-off for the tumour size. But the potential malignancy and the difficulty to individuate the unfavourable cases can be a reason for most urologists to perform an orchiectomy and the TSS remains only an option. The identification of some parameters to discriminate, which tumour can have a malignant behaviour, allows to decide, if a secondary surgery need to be performed and can avoid an unnecessary orchiectomy in patients with lesions, which have a good prognosis. Previous investigators have demonstrated that some histopathological findings can predict malignancy for Leydig cell tumours and that they can be applied to all stromal tumours; tumour size $>5 \mathrm{~cm}$, positive margins, lymph vascular invasion, necrosis, cellular atypia and an increased number of mitoses per high-powered field $(>3)[1,5,11]$.

Furthermore, an age greater than 50 years old seems to be a predictor of increasing risk of malignancy. Rove et al. observed a significant difference, comparing the 5-year occult metastatic disease-free survival in patients with 0 or 1 risk factor to those with 2 or more: $98.3 \%$ vs. $48.1 \%$. Age and tumour size $>5 \mathrm{~cm}$ are the risk factors, that correlate better with the risk to develop disease recurrence or metastases [1]. In our small series of patients with clinical stage I TSCST no pathological risk factor was found, and no patient developed recurrence or metastases. Five patients were over 50 years old. Our experience confirms the previous findings, that TSS could be safely performed, in presence of a TSCST in frozen sections, when the tumour size doesn't exceed $4 \mathrm{~cm}$ and the lesion is easy to resect, leaving sufficient testicular parenchyma. In presence of one or more pathological risk factors in the definitive histology and age over 50 years old a radical surgery with retroperitoneal lymphadenectomy should always be considered [1,3,4]. Although the good prognosis of these tumours we point out the need of a regular follow up.

\section{Conclusion}

Most of the patients with TSCST have a good prognosis. The reported cases show, that testis sparing surgery is safe in selected cases, if frozen sections are available and if the definitive histology shows 0 or 1 risk factors in patients under 50 years. By presence of 2 or more risk factors, more aggressive personalized treatments with surgery and afterwards eventually chemotherapy and radiotherapy should be considered.

\section{References}

1. Rove KO, Maroni PD, Cost CR, Fairclough DL, Giannarini G, et al. (2016) Pathologic risk factor for metastatic disease in postpubertal patients with clinical stage I testicular stromal tumours. Urology 97: 138-144.

2. Acar C, Gurocak S, Sozen S (2009) Current treatment of testicular sex cord-stromal tumours: critical review. Urology 73(6): 1165-1171.

3. Giannarini G, Dieckmann KP, Albers P, Heidenreich A, Pizzocaro G (2010) Organ-sparing surgery for adult testicular tumours: a systematic review of the literature. Eur Urol 57: 780-790.

4. Nicolai N, Necchi A, Raggi D, Biasoni D, Catanzaro M, et al. (2015) Clinical outcome in testicular sex cord stromal tumours: testis sparing surgery vs radical orchiectomy and management of advanced disease. Oncology 85(2): 402-406.

5. Kim R, Young RH, Scully RE (1985) Leydig Cell Tumours of the Testis. A Clinicopathological Analysis of 40 Cases and Review of the Literature. Am J Surg Pathol 9 (3): 177-192.

6. Suardi N, Strada E, Colombo R, Freschi M, Salonia A, et al. (2009) Leydig cell tumour of the testis: presentation, therapy, long-term follow-up and the role of organ-sparing surgery in a single-institution experience. BJU International 103(2): 197-200.

7. Tazi MF, Mellas S, El Fassi MJ, Farih MH (2008) Leydig cell hyperplasia revealed by gynecomastia. Rev Urol 10(2): 164-167.

8. Loeser A, Vergho DC, Katzenberger T, Brix D, Kocot A, et al. (2009) Testissparing surgery versus radical orchiectomy in patients with Leydig cell Tumours. Urology 74(2): 370-372.

9. Banerji JS, Odem-Davis K, Wolff EM, Nichols CR, Porter CR (2016) Patterns of Care and Survival Outcomes for Malignant Sex Cord Stromal Testicular Cancer: Results from the National Cancer Data Base. J Urol 196(4): 1117-1122.

10. Mahon FB Jr, Trinity RG, Madsen PO (1973) Malignant interstitial cell testicular tumor. Cancer 31 (5): 1208-1212.

11. Silberstein JL, Bazzi WM, Vertosick E, Carver BS, Bosl GJ, et al. (2014) Clinical outcomes of local and metastatic testicular sex cord-stromal Tumours. J Urol 192 (2): 415-419. 
ISSN: 2574-1241

DOI: $10.26717 / B J S T R .2018 .11 .002138$

Emanuela Trenti. Biomed J Sci \& Tech Res

(C) (i) This work is licensed under Creative

Submission Link: https://biomedres.us/submit-manuscript.php

\begin{tabular}{ll} 
BIOMEDICAL & Assets of Publishing with us \\
RESEARCHES & - Global archiving of articles \\
\hline - Immediate, unrestricted online access
\end{tabular}

